Bond University

Research Repository

\title{
Strength training for plantar fasciitis and the intrinsic foot musculature: A systematic review
}

Huffer, Dean; Hing, Wayne; Newton, Richard; Clair, Mike

Published in:

Physical Therapy in Sport

DOI:

10.1016/j.ptsp.2016.08.008

Licence:

CC BY-NC-ND

Link to output in Bond University research repository.

Recommended citation(APA):

Huffer, D., Hing, W., Newton, R., \& Clair, M. (2017). Strength training for plantar fasciitis and the intrinsic foot musculature: A systematic review. Physical Therapy in Sport, 24, 44-52.

https://doi.org/10.1016/j.ptsp.2016.08.008

\section{General rights}

Copyright and moral rights for the publications made accessible in the public portal are retained by the authors and/or other copyright owners and it is a condition of accessing publications that users recognise and abide by the legal requirements associated with these rights.

For more information, or if you believe that this document breaches copyright, please contact the Bond University research repository coordinator 


\section{Accepted Manuscript}

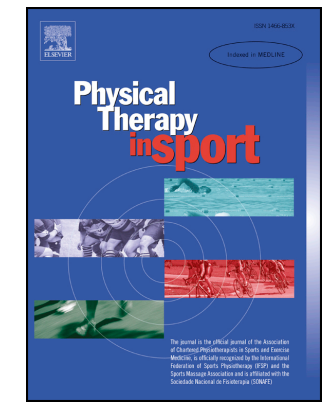

Strength training for plantar fasciitis and the intrinsic foot musculature: A systematic review

Dean Huffer, Wayne Hing, Richard Newton, Mike Clair

PII:

S1466-853X(16)30075-X

DOI:

10.1016/j.ptsp.2016.08.008

Reference: $\quad$ YPTSP 760

To appear in: Physical Therapy in Sport

Received Date: 20 May 2016

Revised Date: 8 August 2016

Accepted Date: 17 August 2016

Please cite this article as: Huffer, D., Hing, W., Newton, R., Clair, M., Strength training for plantar fasciitis and the intrinsic foot musculature: A systematic review, Physical Therapy in Sports (2016), doi: 10.1016/ j.ptsp.2016.08.008.

This is a PDF file of an unedited manuscript that has been accepted for publication. As a service to our customers we are providing this early version of the manuscript. The manuscript will undergo copyediting, typesetting, and review of the resulting proof before it is published in its final form. Please note that during the production process errors may be discovered which could affect the content, and all legal disclaimers that apply to the journal pertain. 
Dear Editor:

Please find attached for your kind review our manuscript entitled "Strength Training for Plantar Fasciitis and the Intrinsic Foot Musculature: A Systematic Review".

To our knowledge this is the first research assessing this novel and clinically relevant intervention. We look forward to your favorable consideration.

Most sincerely,

Dr Wayne Hing

True statement -

All authors meet the criteria for authorship, have approved the final article and all those entitled to authorship are listed as authors. 


\section{$\underline{\text { Primary }}$}

- HUFFER, Dean. MA (ExSci), BDes (Comm)

Doctor of Physiotherapy Student Researcher 2016

Bond University Faculty of Health Sciences \& Medicine, QLD Australia

Residential Address: 44 Main Street, Newry VIC 3859, Australia

Postal Address: $\quad$ P.O. Box 12, Newry VIC 3859, Australia

Telephone: $\quad+61351451359$

Mobile: $\quad+61409508236$

email: $\quad$ dean.d.huffer@gmail.com

\section{Contributing and Corresponding Author}

- $\quad$ HING, Wayne. PhD, MHSc (Hons), ADP (OMT), Dip MT, DipPhys, DipAcu Professor of Physiotherapy, Head of Physiotherapy Program, Bond University email: $\quad$ whing@ $\quad$ bond.edu.au

\section{Contributing Authors continued}

- NEWTON, Richard. M.Phty, BASc (Phty)

Assistant Professor Bond University, APA Titled Sports Physiotherapist, Pindara Physiotherapy \& Sports Medicine, Sports Super Centre Runaway Bay email: rmnewton@ bigpond.net.au

- CLAIR, Mike. D.Phty, BA.Kin (Hons)

Doctor of Physiotherapy Student Researcher 2015), Bond University Active Physiotherapy, Katherine N.T.

email: $\quad$ mclair.physio@gmail.com 
Study Title:

Strength Training for Plantar Fasciitis and the Intrinsic Foot Musculature: A Systematic Review 


\section{ABSTRACT:}

The aim was to critically evaluate the literature investigating strength training interventions in the treatment of plantar fasciitis and improving intrinsic foot musculature strength. A search of PubMed, CINHAL, Web of Science, SPORTSDiscus, EBSCO Academic Search Complete and PEDRO using the search terms plantar fasciitis, strength, strengthening, resistance training, intrinsic flexor foot, resistance training.

Seven articles met the eligibility criteria. Methodological quality was assessed using the modified Downs and Black checklist. All articles showed moderate to high quality, however external validity was low.

A comparison of the interventions highlights significant differences in strength training approaches to treating plantar fasciitis and improving intrinsic strength. It was not possible to identify the extent to which strengthening interventions for intrinsic musculature may benefit symptomatic or at risk populations to plantar fasciitis. There is limited external validity that foot exercises, toe flexion against resistance and minimalist running shoes may contribute to improved intrinsic foot musculature function. Despite no plantar fascia thickness changes being observed through high-load plantar fascia resistance training there are indications that it may aid in a reduction of pain and improvements in function.

Further research should use standardised outcome measures to assess intrinsic foot musculature strength and plantar fasciitis symptoms. 


\section{$\underline{\text { HIGHLIGHTS }}$}

\section{HIGHLIGHTS}

- Plantar fasciitis a common foot condition and affects both elderly and athletic populations.

- Literature proposes that the condition should be termed a fasciosis or fasciopathy.

- An association between intrinsic foot muscle weakness and foot pain has been reported.

- High-load strength training causes high tensile loads across the plantar aponeurosis.

\section{KEY WORDS}

- Plantar Fasciitis (Plantar)

- Heel Pain (Heel)

- Intrinsic Foot Muscles (Intrinsic)

- Resistance Training (Strength) 


\section{$\underline{\text { INTRODUCTION }}$}

Plantar fasciitis is one of the most common musculoskeletal disorders of the foot (Young, 2012; McPoil et al., 2008) treated in primary care (Thing, 2012). It is thought to result from chronic overload either from lifestyle or exercise and affects both elderly and athletic populations (Schwartz, 2014).

The plantar fascia is an aponeurosis that originates from the medial tubercle of the calcaneus and extends distally to the phalanges (Bolgla, 2004). The Windlass Mechanism is a term used to describe how the plantar aponeurosis acts like a pulley (Hicks, 1954), developing tension during dorsiflexion of the great toe. This shortens the distance between the calcaneus and the metatarsals, as the aponeurosis winds around the metatarsal head resulting in elevation the medial longitudinal arch (Bolgla, 2004). Together with the intrinsic foot muscles the plantar aponeurosis stabilises the arch and provides dynamic sensory and motor control to the foot (McKeon, 2015).

In addition to sedentary middle aged patients (Radford et al., 2006), plantar fasciitis is particularly prevalent in running and dancing activities that require maximal plantarflexion of the ankle and dorsiflexion of the metatarsophalangeal joint (Brukner \& Khan, 2012). Symptoms are characterised by pain radiating the medial aspect of the heel into the arch of foot. Pain is often most intense with the first steps of the day or after rest or warming up with activity (Thing, 2012). As the condition progresses these symptoms can become more debilitating reducing the patient's ability to weight bear. Recent literature proposes that the condition should be termed a fasciosis as the pathology more closely resembles that of tendinosis (Schwartz, 2014; Brukner \& Khan, 2012).

Brukner \& Khan (2012) state that despite plantar fasciitis being the most common cause of rear foot (inferior heel pain) differential diagnosis should not overlook other common conditions such as fat pad contusion, and less common conditions such as calcaneal 
stress and traumatic fractures, medial calcaneal nerve entrapment, lateral plantar nerve entrapment, tarsal tunnel syndrome, talar stress fracture, retrocalcaneal bursitis, along with not to be missed pathologies such as spondyloarthropathies, osteoid osteoma and post knee or ankle injury complex pain syndrome (CRPS Type 1). McPoil et al. (2008) include a similar list of differentials, but with the addition of Sever's disease (calcaneal apophysitis) a common cause of heel pain in pediatric patients typically aged 7 - 14 years old (Marachick et al., 2015).

Treatments for plantar fasciitis have been varied, with conflicting evidence (McPoil et al, 2012). Until recently exercise therapy reviews have highlighted the effectiveness of plantar fascia-specific stretching and have indicated it may have limited benefits (Schwartz, 2014; Almubarak, 2012). However, a recent a systematic review found that there is a significant association between intrinsic foot muscle weakness and painful foot pathologies such as plantar fasciitis (Latey et al., 2014). Therefore, the aim of this review is to critically evaluate the literature investigating strength training interventions in the treatment of plantar fasciitis and improving intrinsic foot musculature strength.

\section{$\underline{\text { METHODOLOGY }}$}

\section{Search Strategy}

The systematic review "Strength training for plantar fasciitis and the intrinsic foot musculature" was registered with PROSPERO (No. CRD42016036302). The following bibliographic databases were searched to identify potentially relevant articles: PubMed, CINHAL, Web of Science, SPORTSDiscus, EBSCO Academic Search Complete and PEDRO or all articles up until March 23, 2016.

The database search, literature screening and data extraction was completed by a single researcher $(\mathrm{DH})$. The database search consisted of using the search terms: (“plantar fasciitis") AND (“strength" OR "strengthening" OR "resistance training") and then repeated 
with the search terms ("intrinsic foot muscle" OR "intrinsic flexor foot") AND ("strength" OR “strengthening” OR “resistance training”).

\section{$\underline{\text { Study Selection }}$}

The screening process began with the removal of duplicate articles, before screening articles based on title and abstract against the search terms. The remaining articles were then reviewed as full texts against the following criteria: (i) a specific isolated plantar / IFM strength intervention, and (ii) pre-test and post-test measures to assess the effectiveness of intervention being the only study design requirement.

\section{$\underline{\text { Data Extraction }}$}

Data extraction was performed by using a pre-defined data-abstraction sheet. The following data were extracted: (i) Author (year), (ii) country, (iii) study design, (iv) participants i.e. sample size, demographics, male / female ratio, (v) interventions i.e. intervention groups, exercise prescription (sets / repetitions); (vi) outcome measures; and (vii) main findings (results).

\section{Quality Evaluation}

Study quality was independently assessed by two examiners (MC, DH), with disagreements resolved by consensus. In the case of continued disagreement, a third reviewer was available for arbitration (WH). Quality was assessed using the "Checklist for Measuring Quality" (Downs \& Black, 1998) (Re: Figure 2). The 27 question checklist has been used previously in systematic reviews including various study designs (Crow et al., 2011), and has been shown to have good intra-rater ( $\mathrm{r}$. 0.88) and inter-rater (r . 0.75) reliability (Downs \& Black, 1998). The last item of the checklist examining the power of results was simplified to a score of 0 (no sample size calculation) or 1 (sample size calculation reported) (Deshpande et al., 2008). Therefore, a maximum score of 28 could be achieved for randomised studies and 25 for non-randomised studies. 
Figure 1: Modified Downs \& Black Checklist (Deschpande et al., 2008).

REPORTING: "Yes=1," "No=0"

1. Is the hypothesis / aim / objective of the study clearly described?

2. Are the main outcomes to be measured clearly described in the Introduction or Methods section

3. Are the characteristics of the patients / samples included in the study clearly described?

4. Are the interventions of interest clearly described?

5. Are the distributions of principal confounders in each group of subjects to be compared clearly described? "Yes=2," "Partially=1," "No=0"

6 . Are the main findings of the study clearly described?

7. Does the study provide estimates of the random variability in the data for the main outcomes?

8. Have all important adverse events that may be a consequence of the intervention been reported?

9. Have the characteristics of patients lost to follow-up been described?

10. Have actual probability values been reported (e.g., 0.035 rather than $<0.05$ ) for the main outcomes except where the probability value is less than 0.001 ?

11. Were the subjects asked to participate in the study representative of the entire population from which they were recruited?

EXTERNAL VALIDITY: "Yes=1," "No=0," "Unable to determine=0"

12. Were those subjects who were prepared to participate representative of the entire population from which they were recruited?

13. Were the staff, places, and facilities where the patients were treated, representative of the treatment the majority of patients receive?

INTERNAL VALIDITY - BIAS: "Yes=1," "No=0," "Unable to determine=0"

14. Was an attempt made to blind study subjects to the intervention they have received?

15. Was an attempt made to blind those measuring the main outcomes of the intervention?

16. If any of the results of the study were based on "data dredging" was this made clear?

17. In trials and cohort studies, do the analyses adjust for different lengths of follow-up of patients, or in case-control studies, is the time period between the intervention and outcome the same for cases and controls?

18. Were the statistical tests used to assess the main outcomes appropriate?

19. Was compliance with the intervention/s reliable?

20. Were the main outcome measures used accurate (valid and reliable)?

INTERNAL VALIDITY - CONFOUNDING (Selection Bias): "Yes=1," "No=0," "Unable to determine=0"

21. Were the patients in different intervention groups (trials and cohort studies) or were the cases and controls (case-control studies) recruited from the same population?

22. Were study subjects in different intervention groups (trials and cohort studies) or were the cases and controls (case-control studies) recruited over the same period of time?

23. Were study subjects randomised to intervention groups?

24. Was the randomized intervention assignment concealed from both patients and health care staff until recruitment was complete and irrevocable?

25. Was there adequate adjustment for confounding in the analyses from which the main findings were drawn?

26. Were losses of patients to follow-up taken into account?

POWER

27. Did the study have sufficient power to detect a clinically important effect where the probability value for a difference being due to chance is less than $5 \%$ ?

\section{$\underline{\text { Data Analysis }}$}

Due to the heterogeneous nature of the included studies (i.e. varying study designs, interventions, outcome measures, and quality of data), a quantitative analysis was unfeasible. The following cut-off points have been reported to categorise studies by quality: excellent (26-28), good (20-25), fair (15-19) and poor ( $\leq 14)$ (Hooper, 2008; Chudyk et al., 2009). 
Quality Index

Percentage

\section{Strong}

Moderate

Limited

Poor

$75 \%+$

$50-74 \%$

$25-49 \%$

$<25 \%$
Methodological Quality Score

$21+$
$14-20$
$7-13$
$<7$

Table 1: Categorisation of total methodological scores with Downs \& Black checklist.

Adapted from (Hartling et al., 2004).

\section{$\underline{\text { RESULTS }}$}

Combined searches literature searches produced a total of 226 articles, and once duplicates were removed (94 excluded) this was reduced to 132 eligible articles. Articles were then screened by title ( 92 excluded), abstract ( 11 excluded), and then 29 articles full text articles were obtained for review against the inclusion criteria "(i) specific isolated plantar / IFM strength intervention, and (ii) pre-test and post-test measures to assess the effectiveness of intervention" with a further 22 articles being excluded. A total of seven clinical trials published in peer-reviewed journals were retained for review at the completion of the literature screening process.

Figure 2: Flow diagram of literature screening process.

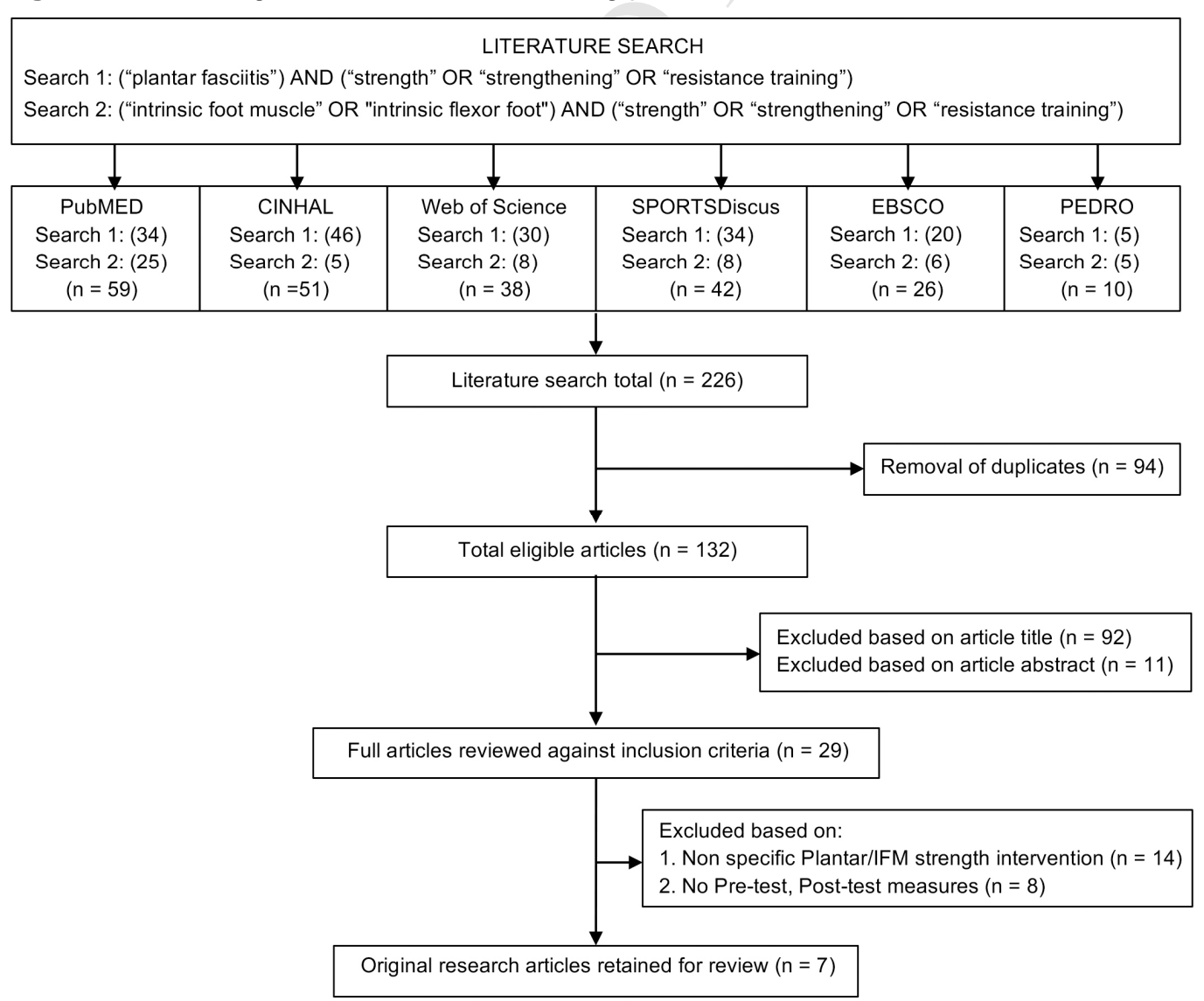




\section{Methodological Quality}

All seven articles were assessed against the Down's and Black checklist and attained a score of either moderate or high quality. Four of the seven articles were deemed to be high quality articles (score > 21). The other three articles were deemed to be of moderate quality (score >14). The main areas of weakness in all seven studies was their external validity and power analysis of the Modified Downs and Black checklist. Internal validity of all seven articles was fairly poor as well. Additionally, only five of the seven articles attempted to blind those measuring the main outcomes of the intervention.

\section{$\underline{\text { Study Characteristics }}$}

The studies included four randomised control trials (RCTs) (Lynn et al., 2012; Miller et al., 2014; Rathleff et al., 2014; Johnson et al., 2015) and three pre/post-test designs (Hashimoto et al., 2014; Mulligan et al., 2013; Skou et al., 2012).

All studies had substantial differences in their strengthening interventions for plantar heel pain and the intrinsic foot musculature from their approach, exercise prescription / progression and timeframe. In broad terms the eight articles could be grouped into three interventional approach categories: 1. Minimalist running shoe IFM strengthening (Miller et al., 2014., Johnson et al., 2015), 2. IFM foot exercises (Lynn et al., 2012; Mulligan et al., 2013; Hashimoto et al., 2013), and 3. Plantar aponeurosis loading (Skou et al., 2012; Rathleff et al., 2014). Four of these seven studies stipulated loading progressions for the intervention over the duration of the study.

\section{Minimalist running shoe IFM strengthening}

The differences in minimalist running shoes interventions (Miller et al., 2014., Johnson et al., 2015) included minimal running shoe allocation, mileage prescription and intervention duration. Miller et al. (2014) provided a range of minimal running with a $4 \mathrm{~mm}$ heel-to-toe offset or less. It also stipulated a precise 30 miles $(48 \mathrm{~km})$ per week running total 
volume over 12-weeks. In comparison the Johnson et al. (2015) prescribed a specific 0mm heel-to-toe offset minimal running shoe model (Vibram Five Fingers), and a mileage range 15-30miles (24-48km) over its 10-week duration.

\section{IFM foot exercises}

The IFM strengthening in response to a foot exercises load included three exercise intreventions (Hashimoto et al., 2014), towel curl exercises (Lynn et al., 2012) short foot exercises (SFE) (Lynn et al., 2012; Mulligan et al., 2013). The SFE, along with the heel raise variations in the (Skou et al., 2012; Rathleff et al., 2014) were the only exercises appearing in more than a single study. The SFE intervention consisted of shortening the foot without curling the toes to elevate the arch, with care to avoid engaging the long toe flexors. The intervention was submaximal exercise that relied on technique for IFM activation rather than power (Mulligan et al., 2013).

\section{Plantar aponeurosis loading}

The plantar aponeurosis loading interventions (Skou et al., 2012; Rathleff et al., 2014) exercise consisted of a single leg heel raise protocol, with toes dorsiflexed under cloth (Skou et al., 2012) and towel (Rathleff et al., 2014). This loading approach was inspired by the Carlson et al., (2000) research into the biomechanical relationship between the tendoachilles, plantar fascia and metatarsophalangeal joint dorsiflexion angle. However, Rathleff et al. (2014) was a longer duration study with one, two, three and 12-month follow-ups and was progressed with loading a backpack with books. While the Skou et al. (2012) was only a time-of-day intervention.

Therefore, all seven studies were clinically and therapeutically heterogeneous, necessitating a qualitative analysis for summarizing the results. Table 2 provides a summary of the included studies. 
Table 2: Summary of included studies

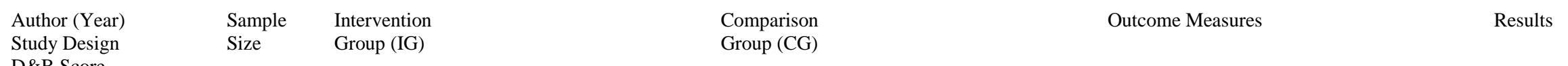

D\&B Score

Toe flexion Interphalangeal /

Metatarsophalangeal joints $3 \mathrm{~kg}$ load.

8 wks

3days/wk

200reps/day

$\begin{array}{lll}\text { Johnson et al. (2015) } & \mathrm{n}=37 & \mathrm{n}=18 \\ \text { RCT } & & \text { Transitioned to Vibram Five Fingers (VFF) } \\ \text { 23/28 } & & \text { (0mm heel-to-toe offset) } \\ & & \text { 10wks: } 24-48 \mathrm{kms} \text { running/wk }\end{array}$

$\mathrm{n}=19$

Ran in preferred traditional running shoes (12mm heel-to-toe offset)

10wks: 24-48kms running/wk

$\begin{array}{lll}\text { Lynn et al. (2012) } & \mathrm{n}=24 & \text { Short Foot Exercise (SFE) } \mathrm{n}=8 \\ \text { RCT } & \cdot & \text { Towel Curl Exercises (TCE) } \mathrm{n}=8 \\ 19 / 28 & & \text { 4wks: } 100 \text { reps/day for both groups }\end{array}$

- Digital grip dynamometer

- Foot arch measurements (longitudinal and horizontal planes) during static standing using the Berkemann footprint.

- Dynamic test items: single leg long jump, vertical jump, and $50 \mathrm{~m}$ dash.

- Ultrasonography measurements of abductor hallucis (ABDH), flexor digitorium drevis (FDB), flexor hallucis brevis (FHB), extensor digitorium brevis (EDB) thickness

- Magnetic resonance imaging (MRI) of Bone Marrow Oedema scores (BME)

- Total range of movement of the center of pressure in mediolateral direction for a static-balance test and a dynamic balance test on a force plate

- Navicular height in weight-bearing

$\begin{array}{llll}\text { Miller et al. (2014) } & \mathrm{n}=33 & \mathrm{n}=17 & \mathrm{n}=16 \\ \mathrm{RCT} & & \text { Transitioned to running in minimal shoes } & \text { Ran in traditional running shoes } \\ \text { 22/28 } & \text { (4mm or less heel-to-toe offset) } & \text { 12wks: 30miles running/wk } \\ & & \end{array}$

- Significant changes observed for intrinsic foot flexor strength scores, foot arches, vertical jumping, single leg long jumping, and $50 \mathrm{~m}$ dash time.

- Significant increase in ABDH cross sectional area in the Vibram Five Fingers (minimalist running shoe) group ( $p=$ $0.01)$

- No significant changes in the other muscles measured $(p>0.05)$.

- Bone marrow oedema developed primarily in females who has significantly smaller size in all muscles $(\mathrm{p} \leq 0.05)$.

- Static-balance test and navicular-height test were not affected by training the intrinsic form muscles (IFM).

- Dominant limb: Small improvement in performance for all 3 groups during the second testing.

- Non-dominant limb, dynamic-balance test performance only improved in the 2 exercise groups. Short foot exercise (SFE) group improved much more than the Towel curl exercise (TCE) group.

- Running kinematics - captured on a standard treadmill using an eight-camera Vicon MX T10 3D motion capture system.

- Arch height index in sitting and standing to calculate relative arch deformation

$$
\frac{\text { AHsit-AHss }}{\text { AHsit }} \times\left(\frac{10^{4}}{\mathrm{BM}}\right)
$$

- MRI to measure cross-sectional area and muscle volumes of abductor hallicus (ADH), flexor digitorum brevis (FLDB), and abductor digiti minimi (ABDM)
- CG: Foot strike pattern did not change IG: Shifted to a more mid-foot strike or fore-foot strike pattern.

- FDB became larger in both groups: $\mathrm{CG}=11 \% \mathrm{IG}=21 \%$

- ABDM became larger in minimally shod runners. $\mathrm{IG}=22 \%$

Significantly increased longitudinal arch stiffness $(60 \%)$ in minimally shod runners. 
Mulligan et al. (2013) $\quad n=21 \quad$ Short Foot Exercises (SFE)

Pre/post

$25 / 28$

approximately 30reps/day.

Progressed: from sitting to double limb

stance (DLS) to single limb stance (SLS)

when 3 mins obtained.

\section{Rathleff et al. (2014) \\ $\mathrm{n}=48$}

$\mathrm{RCT}$

$23 / 28$

Skou et al. (2012)

$\mathrm{n}=10$

Pre/post-test

$20 / 28$ heel down phase).
Strength: $\mathrm{n}=24$

Follow-ups:

$1 \mathrm{mth}: \mathrm{n}=22$

3mths: $\mathrm{n}=18$,

6mths: $\mathrm{n}=17$,

12mths: $\mathrm{n}=18$

Strength group (shoe inserts and high-load strength training)

Every 2 nd day: 3 sets of 12 reps

(3sec concentric heel raise, $3 \mathrm{sec}$ eccentric

2wks: Load increased (backpack/books) fo 4 sets of 10 , then at 4 wks: 5 sets of 8 .

Sub-study 2: Unilateral heel raise with toes dorsi-flexed by placing a folded dishcloth under toes.

12 reps ( $3 \mathrm{sec}$ concentric heel raise, $3 \mathrm{sec}$ eccentric heel down phase) approx. 90sec per set with 3 sets, and 2 mins recovery

between sets.
Navicular drop (ND) difference between the seated and standing navicular

positions

- Arch Height Index (AHI) calculated by dividing the dorsum foot height by the runcated length of the foot to form a ratio in both the seated and standing positions

- Intrinsic Foot Musculature Test

- Arch rigidity index (ARI), represents the structural mobility of the MLA. This ratio is calculated by dividing the standing $\mathrm{AHI}$ by the sitting AHI

- Star excursion balance test

Primary Outcome

Foot Function Index (FFI)

Self report questionnaire

Follow-ups:

$1 \mathrm{mth}: \mathrm{n}=23$,

3mths: $\mathrm{n}=2$,

6mths: $n=20$

12mths: $\mathrm{n}=20$

- Secondary Outcomes:

Ultrasonography measurements of planta fascia thickness at 1,3 and $6 \mathrm{mths}$,

tretch group (shoe inserts and plantar fascia stretching)

FFI: Item 1 (foot pain at worst) and Item 2

(foot pain during first step in the

morning).

Sub-study 2: Ultrasonography measurements of plantar fascia thickness prior, immediately after, and $3 \mathrm{hrs}$ postexercise.
- Subject ND decreased by a mean of $1.8 \mathrm{~mm}$ at $4 \mathrm{wks}$ and $2.2 \mathrm{~mm}$ at $8 \mathrm{wks}$ ( $\mathrm{p}<$ $0.05)$

- AHI increased from 28 to $29 \%$ ( $p<0.05$ )

- Intrinsic foot muscle performance during a static unilateral balancing activity improved from a grade of fair to good ( $p$ $<0.001)$

- Significant improvement during a functional balance and reach task in al directions with the exception of an anterior reach $(\mathrm{p}<0.05)$

- At the primary endpoint the strength group had a FFI that was 29-points lower $(\mathrm{p}, 0.05)$ compared with the stretch group.

- There were no differences in any of the secondary outcomes.

Plantar fascia thickness did not change in relation to Sub-study 2: high-load strength raining.

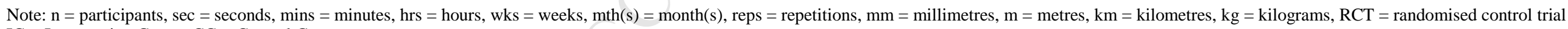
IG = Intervention Group, $\mathrm{CG}=$ Control Group 
Table 3: Sample population characteristics

\begin{tabular}{|c|c|c|c|c|c|c|}
\hline \multirow[b]{2}{*}{ Author / Country } & \multirow[b]{2}{*}{ Sample Population } & \multirow[b]{2}{*}{$\begin{array}{l}\text { Gender } \\
(\mathrm{M}: \mathrm{F})\end{array}$} & \multicolumn{4}{|c|}{ Sample Mean (Standard Deviation) } \\
\hline & & & $\begin{array}{l}\text { Age } \\
\text { (yrs) }\end{array}$ & $\begin{array}{l}\text { Height } \\
(\mathrm{cm})\end{array}$ & $\begin{array}{l}\text { Weight } \\
(\mathrm{kg})\end{array}$ & $\begin{array}{l}\text { BMI } \\
\left(\mathrm{kg} / \mathrm{m}^{2}\right)\end{array}$ \\
\hline $\begin{array}{l}\text { Hashimoto et al. (2014) } \\
\text { Japan }\end{array}$ & $\begin{array}{l}\text { Healthy males without motor } \\
\text { system disease or sport } \\
\text { history. }\end{array}$ & $12: 0$ & $29.0( \pm 5.0)$ & $172.5( \pm 7.3)$ & $64.9( \pm 12.8)$ & 21.5 \\
\hline $\begin{array}{l}\text { Johnson et al. (2015) } \\
\text { U.S.A. }\end{array}$ & $\begin{array}{l}\text { Recreational runners } \\
\text { completing an average of } \\
24-48 \mathrm{~km} / \text { wk running for } \\
6 \mathrm{mths} \text { prior. } \\
\text { Exclusion criteria: Previous } \\
\text { use of minimal running shoes } \\
\text { or a lower extremity injury } \\
\text { that prevented running for } \\
>3 \text { days } / \text { wk during the } \\
\text { previous } 6 \text { mths. }\end{array}$ & $10: 8^{*}$ & $26( \pm 6)$ & $174( \pm 1)$ & $70( \pm 13)$ & 23.1 \\
\hline $\begin{array}{l}\text { Lynn et al. (2012) } \\
\text { U.S.A. }\end{array}$ & $\begin{array}{l}\text { Healthy university-age } \\
\text { volunteers with no history of } \\
\text { major lower limb pathology or } \\
\text { balance impairment. }\end{array}$ & $10: 14$ & & 172.0 & $68.2( \pm 9.8)$ & 23.2 \\
\hline $\begin{array}{l}\text { Miller et al. (2014) } \\
\text { S.A }\end{array}$ & $\begin{array}{l}\text { Healthy runners running an } \\
\text { average } 30 \text { miles( } 48 \text { miles)/wk } \\
\text { running in a standard running } \\
\text { shoe for more than } 12 \mathrm{mths} \\
\text { prior. }\end{array}$ & $17: 16$ & & 177.1 & 69.8 & 22.3 \\
\hline $\begin{array}{l}\text { Mulligan et al. (2013) } \\
\text { U.S.A. }\end{array}$ & $\begin{array}{l}\text { Asymptomatic to foot pain, } \\
\text { PFPS, tibialis anterior or } \\
\text { posterior dysfunction or } \\
\text { neurological disease within } \\
\text { past } 3 \text { mths. } \\
\text { Average weekly training days } \\
\text { 5.94days per/wk }\end{array}$ & $3: 18$ & $26.1( \pm 5.0)$ & $168.4( \pm 7.1)$ & $69.3( \pm 13.5)$ & 24.4 \\
\hline $\begin{array}{l}\text { Rathleff et al. (2014) } \\
\text { Denmark }\end{array}$ & $\begin{array}{l}\text { Over } 18 \text { yrs, non-pregnant } \\
\text { with: } \\
\text { (i) history of heel pain for at } \\
\text { least } 3 \text { mths prior } \\
\text { (ii) pain on palpation of the } \\
\text { medial calcaneal tubercle or } \\
\text { the proximal plantar fascia. } \\
\text { (iii) }>4 \mathrm{~mm} \text { plantar fascia } \\
\text { thickness. } \\
\text { No history of systemic } \\
\text { diseases, prior heel surgery, } \\
\text { corticosteroid injections into } \\
\text { plantar fascia (within } 6 \mathrm{mths} \text { ). }\end{array}$ & $16: 32$ & $46.0( \pm 8.0)$ & $172.1( \pm 8.9)$ & $79.6( \pm 12.8)$ & $27.1( \pm 8.9)$ \\
\hline $\begin{array}{l}\text { Skou et al. (2012) } \\
\text { Denmark }\end{array}$ & $\begin{array}{l}\text { No history of aponeurosis } \\
\text { plantaris pedis pain. }\end{array}$ & $5: 5$ & $31.2( \pm 6.5)$ & - & - & $22.2( \pm 6.5)$ \\
\hline
\end{tabular}

Note: $\mathrm{M}=$ male, $\mathrm{F}=$ female, $\mathrm{wks}=$ weeks, $\mathrm{mths}=$ months, $\mathrm{yrs}=$ years, $\mathrm{mm}=$ millimetres, $\mathrm{m}=$ metres, $\mathrm{km}=$ kilometres, $\mathrm{kg}=$ kilograms, PFPS = patellofemoral pain. 


\section{$\underline{\text { Sample Characteristics }}$}

All together the seven studies included a total of 185 participants with a slightly higher female portion reported (51.6\%). Hashimoto et al. (2014) was the only gender specific study (12 males). Rathleff et al. (2014) differed from the other studies with an older (mean age 46years \pm 8.0 ) and symptomatic plantar fasciitis sample population with greater body mass indexes (BMI's) $27.1 \mathrm{~kg} / \mathrm{m}^{2}( \pm 8.9)$. In contrast the other studies all had young (mean ages between 23.0 and 31.2 years) healthy - BMI between 18.50 - 24.99 (World Health Organization, 2015) asymptomatic patients (no history of plantar fasciitis / heel pain). The sample sizes of the studies were small and ranged from 12 to 48 participants, therefore reducing the validity of the studies' statistical conclusions. Table 3 contains details of the sample population characteristics.

\section{$\underline{\text { Outcome Measures }}$}

A total of 18 outcome measures were identified across the eight reviewed studies. Toe dynamometry (Toe flexor strength) was the only direct strength measure with excellent inter-rater reliability (ICC value of 0.98) reported by Hashimoto et al. (2014).

Indirect IFM functional measures included Intrinsic Foot Musculature Test (Mulligan et al., 2013), Navicular height in standing (Lynn et al., 2012), Navicular drop (Mulligan et al., 2013), Arch Height Index (Mulligan et al., 2013), Arch rigidity index (Mulligan et al., 2013), Relative arch deformation (Miller et al., 2014), Lower limb physical performance tests: Star excursion balance test (Mulligan et al., 2013), The modified Star Excursion (Y-Balance) Test (Lynn et al., 2012), Single legged long jump (Hashimoto et al., 2014), Vertical jump (Hashimoto et al., 2014) and 50-metre dash (Hashimoto et al., 2014).

Ultrasonographic Imaging (USI) and Magnetic Resonance Imaging (MRI) were 
the other two objective measures implemented across the studies with different objectives. USI to measure plantar fascia thickness (Skou et al., 2012; Rathleff et al., 2014) and cross sectional areas of IFM (Johnson et al. 2015). MRI was used to measure cross sectional areas of IFM (Miller et al., 2014) and employed by Johnson et al., (2015) to calculate Bone Marrow Oedema scores (BMES), a four point radiology scale $(0=$ no oedema, 1=remodeling, $2=$ stress reaction , $3=$ stress fracture, and $4=$ full fracture).

Rathleff et al., (2014) implemented the only subjective measure, the Functional Foot Index (FFI). The FFI is a self-report questionnaire that assesses multiple dimensions of foot function (Budiman-Mak et al., 1991). The FFI consists of 23 items divided into three subscales that quantify the impact of foot pathology on pain, disability, and activity limitation. The scores range from 0 to 230 , with 0 reflecting no pain, disability, or activity limitations (Budiman-Mak et al., 1991). The minimal important change is 7-points for the total scale (Landorf \& Radford, 2008).

\section{Clinical Benefits}

Five of the seven studies found evidence of IFM strengthening gains in response to the strengthening interventions (Lynn et al., 2012; Mulligan et al., 2013; Hashimoto et al., 2014; Miller et al., 2014, Johnson et al., 2015).

In respect to plantar fasciitis / heel pain Rathleff et al. (2014) found a 29-point improvement on the strengthening intervention group on the FFI compared to stretching group at the primary study endpoint at three months. Skou et al. (2012) found no change in USI measurements of plantar fascia thickness immediately after, while Rathleff et al. (2014) found no significant changes between the stretching and strengthening intervention groups plantar fascia thickness. 


\section{$\underline{\text { DISCUSSION }}$}

A comparison of the interventions presented in the reviewed studies highlights significant differences in strength training approaches to treating plantar fasciitis and improving intrinsic foot musculature strength. Latey et al. (2014) documented a link between intrinsic foot muscle weakness and painful foot pathologies such as plantar fasciitis. However, Rathleff et al. (2014) was the only study that examined a symptomatic population. It was also of particular significance given that high-load strength training that causes high tensile loads across the tendon has shown promising results on degenerative tendon disorders such as achilles and patellar tendinopathy (Cook \& Purdam, 2009; Malliaras et al., 2013).

The external validity of the studies is limited due to the non-sampling of at risk populations for plantar fasciitis. Riddle et al. (2003) described the main risk factors for plantar fasciitis as reduced ankle dorsiflexion, obesity (BMI $>30 \mathrm{~kg} / \mathrm{m}^{2}$ ) and workrelated weight-bearing. Despite Riddle et al. (2003) concluding that reduced ankle dorsiflexion appears to be the most important risk factor, Rathleff et al. (2014) reported a greater reduction on the FFI symptoms from a strengthening intervention at the primary study endpoint ( 3 months) in comparison to stretching interventions. There were no significant differences in any of the secondary outcomes in Rathleff et al. (2014) study including USI of plantar fascia thickness at one, three and six months and FFI: Item 1 (foot pain at worst) and Item 2 (foot pain during first step in the morning).

In terms of athletic populations, it has been found that the relative risk of injury increases significantly in males and females running greater 40 miles $(64 \mathrm{~km})$ per week (Macera, 1989) which is still considered low-mileage in distance running terms. Both Miller et al. (2014) 30miles(48km) and Johnson et al. (2015) 15-20miles(24-48km) prescribed much lower weekly volumes and therefore reducing the validity of their 
results to distance runners. The studies did show promising results in hypertrophy of abductor halluces (Johnson et al. 2015), flexor digitorum brevis muscles, abductor digiti minimi and significantly increased longitudinal arch stiffness (Miller et al., 2014). It should be acknowledged that Johnson et al., 2015 documented that pre IFM strength was also a factor in a safe transition to minimal running shoes, with some participants (primarily woman with smaller IFM) developing bone marrow oedema in response to the intervention.

Knapik et al., (2016) recently reported that despite impact forces generally being lower in minimally shod shoes that the findings were inconclusive in regard to impact forces, loading and injury rates. Along with the lack of research into the safety and effectiveness of minimal running shoes in symptomatic populations with IFM weakness related pathologies such as plantar fasciitis, the duration of these studies was also limited for a condition that may debilitate for months on end.

The main limitation of a systematic review of the effectiveness of the strengthening interventions for IFM and plantar fasciitis / heel pain is the variance in outcome measures. There is a focus on not only assessing strength of the IFM muscles but also their function in the literature with a number of outcome measures. Unfortunately, these are not uniform across the studies. Rathleff et al. (2014) was the only study to implement an outcome measure that took into account the effect of pain that is often described as the most debilitating component of plantar fasciitis (McPoil et al., 2008).

The narrative article by (McKeon et al., 2014), propose a new paradigm by which to view foot function, assessment, and treatment as one. McKeon et al., (2014) claim that methods of assessing toe flexion strength are inherently limited by the 
inability to conclusively separate the contributions of intrinsic and extrinsic toe flexor muscles.

There is a strong need for future studies regarding investigating strength training interventions in the treatment of plantar fasciitis and the improving intrinsic foot musculature strength to use consistent outcome measures and to examine at risk populations. Study outcome measures should address the following: (i) objective: functional performance, (ii) subjective: functional performance (i.e. pain/limiting factors) and (iii) intrinsic foot muscle strength. Future research into strength training interventions in the treatment of plantar fasciitis and the improving intrinsic foot musculature strength should target symptomatic and at risk populations.

\section{$\underline{\text { SUMMARY }}$}

Based on the studies reviewed it was not possible to identify the extent to which strengthening interventions that improve intrinsic foot musculature may benefit symptomatic or at risk populations to plantar fasciitis / heel pain.

There is limited external validity that short foot exercises (Lynn et al., 2012; Mulligan et al., 2013) toe flexion of all interphalangeal and metatarsophalangeal joints against resistance (Hashimoto et al., 2014) contribute to improved intrinsic foot musculature functional performance when assessed against a variety of outcome in young healthy asymptomatic adults.

Minimal running shoes (Miller et al., 2012; Johnson et al., 2014) have also shown hypertrophic changes in IFM in asymptomatic populations. However, more research is needed for their effectiveness and safety of their prescription in symptomatic populations with foot weakness related pathologies such as plantar fasciitis.

Despite no plantar fascia thickness changes being observed through high-load plantar fascia resistance training (Skou et al., 2012; Rathleff et al., 2014) there are 
indications that it may aid in a quicker reduction of pain and improvements in function (Rathleff et al., 2014).

Further research should use standardised outcome measures to assess intrinsic foot musculature strength and plantar fasciitis symptoms. 


\section{REFERENCES}

Almubarak, A. (2012). Exercise therapy for plantar heel pain. International Journal of Exercise Science, 5(3): 276-289.

Bolgla L. A., \& Malone T. R. (2004) Plantar fasciitis and the windlass mechanism: a biomechanical link to clinical practice. Journal of Athletic Training, 39(1): 77-82.

Brukner, P., Khan, K., \& Brukner, P. (2012). Brukner \& Khan's Clinical Sports Medicine, Sydney: McGraw-Hill.

Budiman-Mak, E., Conrad, K, J., Roach, K, E. (1991) The foot function index: a measure of foot pain and disability. Journal of Clinical Epidemiology, 44, 561570.

Chudyk, A., Jutai, J., Petrella, R., \& Speechley, M. (2009). Systematic review of hip fracture rehabilitation practices in the elderly. Archives of Physical Medicine and Rehabilitation, 90(2): 246-262.

Cook, J. L., \& Purdam, C. R. (2009). Is tendon pathology a continuum? A pathology model to explain the clinical presentation of load-induced tendinopathy. British Journal of Sports Medicine, 43(6): 409-416.

Downs, S.H., \& Black, N. (1998). The feasibility of creating a checklist for the assessment of the methodological quality both of randomized and nonrandomized studies of health care interventions. Journal of Epidemiology \& Community Health, 52, 377-384.

Ellis, R., \& Hing, W. (2008). Neural mobilization: A systematic review of randomized controlled trials with an analysis of therapeutic efficacy. Journal of Manual \& Manipulative Therapy, 16(1): 8-22. 
Hashimoto, T., \& Sakuraba, K. (2014). Strength training for the intrinsic flexor Muscles of the foot: Effects on muscle strength, the foot arch, and dynamic parameters before and after the training. Journal of Physical Therapy Science, 26(3): 373.

Hartling, L., Brison, R. J., Crumley, E. T., Klassen, T. P., \& Pickett, W. (2004). A systematic review of interventions to prevent childhood farm injuries. Pediatrics, 114(4): e483-e496.

Hicks, J, H. (1954). The mechanics of the foot, II: the plantar aponeurosis and the arch. Journal of Anatomy. 88, 25-30.

Johnson, A., Myrer, J., Mitchell, U., Hunter, I., \& Ridge, S. (2015). The effects of a transition to minimalist shoe running on intrinsic foot muscle size. International Journal of Sports Medicine, 37(02).

Knapik, J., Orr, R,, Pope, R., \& Grier, T. (2016). Injuries and footwear (Part 2):

Minimalist running shoes. Journal of Special Operations Medicine, 16(1): 89-96.

Kuligowski, L., Lephart, S., Giannatonio, F., \& Blanc, R. (1998). Effects of whirlpool therapy on the signs and symptoms of delayed-onset muscle soreness. Journal of Athletic Training, 33(3): 222-228.

Latey, P. J., Burns, J., Hiller, C., \& Nightingale, E. J. (2014). Relationship between intrinsic foot muscle weakness and pain: a systematic review. Journal of Foot and Ankle Research, 7(1): A51.

Lemont, H., Ammirati, K., \& Usen, N. (2003). Plantar Fasciitis. Journal of the American Podiatric Medical Association, 93(3): 234-237.

Lynn, S. K., Padilla, R.A., \& Tsang, K. K., (2012). Differences in static- and dynamicbalance task performance after 4 weeks of intrinsic-foot-muscle training: the 
short-foot exercise versus the towel-curl exercise. Journal of Sport Rehabilitation, Nov; 21(4): 327-33.

Lysholm, J. \& Wiklander, J. (1987). Injuries in runners. The American Journal of Sports Medicine, 15(2): 168-171.

Macera, C. (1989). Predicting lower-extremity injuries among habitual runners. Archives of Internal Medicine, 149(11): 2565-2568.

Malliaras, P., Barton, C. J., Reeves, N. D., \& Langberg, H. (2013). Achilles and patellar tendinopathy loading programmes. Sports Medicine, 43(4): 267-286.

Marchick, M., Young, H., \& Ryan, M. (2015). Sever's disease: An underdiagnosed foot injury in the pediatric emergency department. Open Journal of Emergency Medicine, 03(04), 38-40.

McKeon, P., \& Fourchet, F. (2015). Freeing the foot. Clinics in Sports Medicine, 34(2): $347-361$.

McPoil, T., Martin, R., Cornwall, M., Wukich, D., Irrgang, J., \& Godges, J. (2008). Heel pain - Plantar fasciitis. Journal Orthopedic \& Sports Physical Therapy, 38(4), A1-A18.

Miller, E., Whitcome, K., Lieberman, D., Norton, H., \& Dyer, R. (2014). The effect of minimal shoes on arch structure and intrinsic foot muscle strength. Journal of Sport and Health Science, 3(2): 74-85.

Mulligan, E. P., \& Cook, P. G. (2013). Effect of plantar intrinsic muscle training on medial longitudinal arch morphology and dynamic function. Manual Therapy, 18(5): 425-430. 
Radford, J., Landorf, K., Buchbinder, R., \& Cook, C. (2006). Effectiveness of low-dye taping for the short-term treatment of plantar heel pain: a randomised trial. BMC Musculoskeletal Disorders, 7(1).

Rathleff, M., Mølgaard, C., Fredberg, U., Kaalund, S., Andersen, K., \& Jensen, T. et al. (2014). High-load strength training improves outcome in patients with plantar fasciitis: A randomized controlled trial with 12-month follow-up. Scandinavian Journal of Medicine \& Science in Sports, 25(3), e292-e300.

Reid, S., \& Rivett, D. (2005). Manual therapy treatment of cervicogenic dizziness: A systematic review. Manual Therapy, 10: 4-13.

Riddle, D.L., Pulisic, M., Pidcoe, P \& Johnson, R.E. (2003) Risk factors for plantar fasciitis: A matched case-control study. Journal of Bone \& Joint Surgery of America, May; 85 (5): 872 -877.

Schwartz, E. (2014). Plantar fasciitis: A concise review. The Permanente Journal, e105e107.

Skou, S. T., Rathleff, M. S., Moelgaard, C. M., Rasmussen, S., \& Olesen, J. L. (2012). The influence of time-of-day variation and loading on the aponeurosis plantaris pedis: an ultrasonographic study. Journal of Sports Medicine and Physical Fitness. Oct; 52 (5): 506-12.

Taunton, J. (2002). A retrospective case-control analysis of 2002 running injuries. British Journal of Sports Medicine, 36(2), 95-101.

Thing, J., Maruthappu, M., \& Rogers, J. (2012). Diagnosis and management of plantar fasciitis in primary care. British Journal of General Practitioners, 62(601), 443444. 
World Health Organization. (2015). WHO: Global database on body mass index.

Retrieved 4 December 2015, from

http://apps.who.int/bmi/index.jsp?introPage=intro_3.html

Young, C. (2012). Plantar fasciitis. Annals of Internal Medicine, 156 (1). 


\section{HIGHLIGHTS}

- Plantar fasciitis a common foot condition and affects both elderly and athletic populations.

- Literature proposes that the condition should be termed a fasciosis or fasciopathy.

- An association between intrinsic foot muscle weakness and foot pain has been reported.

- High-load strength training causes high tensile loads across the plantar aponeurosis. 